\title{
Reflexões sobre o processo de municipalização das políticas de saúde: a questão da descontinuidade politico-administrativa
}

Juliana Costa Machado(a) Rosângela Minardi Mitre Cotta ${ }^{(b)}$ Jeferson Boechat Soares ${ }^{(c)}$

\section{Introdução}

Este ensaio aborda um problema concernente à implementação de políticas de saúde pública, a saber, o fenômeno da descontinuidade políticoadministrativa verificada nos municípios brasileiros após a criação do Sistema Único de Saúde (SUS). A decisão de abordar este problema fundamenta-se diretamente nas experiências e vivências dos autores, ao longo dos últimos anos, em projetos de pesquisa e de extensão realizados em municípios afetados, de alguma forma, pelo fenômeno acima mencionado, destacando-se as experiências mais recentes referentes ao desenvolvimento do projeto intitulado "Adesão ao tratamento da hipertensão arterial: o papel estratégico da educação em saúde e nutrição na atenção primária".

$\mathrm{Na}$ área das políticas sociais, a saúde foi a que mais avançou significativamente rumo à descentralização e municipalização da gestão impulsionada pelo Movimento de Reforma Sanitária (MRS), na segunda metade da década de 1970, culminando na promulgação da Constituição de $1988^{1-3}$. A discussão teve como pauta central a necessidade de democratização do acesso à saúde, bem como a importância da participação social e da descentralização nos processos de gestão ${ }^{4}$. Tais princípios foram adotados no texto constitucional, o que deu início a construção de um arcabouço jurídico e institucional amplamente analisado na literatura científica nacional, destacando-se a criação dos conselhos municipais de saúde nos três níveis de governo: o municipal, o estadual e o federal ${ }^{5}$.

Mas, o processo de descentralização tornou evidente certas necessidades de aperfeiçoamento para o exercício da participação social, já que a mesma envolve, necessariamente, o desenvolvimento de certas capacidades para que seja possível o exercício da ação coletiva. Faz-se necessário formar capital humano, desenvolver, nas pessoas envolvidas com a gestão da saúde, habilidades e competências, conhecimentos e atitudes, proporcionando o que ficou conhecido na literatura científica como empoderamento ${ }^{6,7}$.

Para a viabilização do empoderamento, destaca-se o potencial das metodologias ativas de ensino e aprendizagem que têm por finalidade a formação de cidadãos conscientes de direitos e deveres, capazes de compreender

\footnotetext{
(a) Doutoranda, Programa de Pós-Graduação em Ciência da Nutrição, Centro de Ciências Biológicas, Universidade Federal de Viçosa (UFV). Campus Universitário, s/n. Viçosa, MG, Brasil. 313899-2899.

juboechat@yahoo.com.br (b) Departamento de Nutrição e Saúde, Centro de Ciências Biológicas, UFV. Viçosa, MG, Brasil. rmmitre@ufv.br

(c) Departamento de Ciências Sociais, Centro de Ciências Humanas, UFV. Viçosa, MG, Brasil. jeferson.boechat@ufv.br
} 
e analisar criticamente contextos, agendas e a implementação de políticas públicas, tornando possível o controle social da gestão da saúde . $^{2}$.

O empoderamento, portanto, visa a consolidação da virtude cívica, que é um atributo da ação de indivíduos que se ocupam com questões coletivas 9 . A virtude cívica é importante para a implementação da gestão da saúde pública nos municípios porque indica a ocorrência da participação social.

Todo o processo iniciado com o MRS resultou na implantação de um modelo de descentralização do SUS, a ponto de ser possível afirmar, segundo Arretche ${ }^{10}$, que “... os governos locais já assumiram a gestão da atenção básica à saúde" (p. 332).

É exatamente em um contexto de municipalização que os autores puderam constatar, por meio de suas respectivas experiências profissionais, a ocorrência da descontinuidade político-administrativa. $\mathrm{E}$ trata-se de um conjunto de experiências para as quais, inicialmente, não foi possível obter muitos esclarecimentos. Isto porque, de acordo com Nogueira ${ }^{11}$, não é comum que o problema da descontinuidade seja abordado, na literatura científica, com ferramentas teóricas bem definidas.

O objetivo deste ensaio é apresentar uma reflexão sobre o fenômeno da descontinuidade administrativa, procurando identificar seus possíveis elementos, a saber, os problemas referentes à governabilidade e à governança em nível municipal. Parte integrante dessa reflexão é a sugestão de um modelo analítico para a realização de levantamentos primários, que são concebidos como o início de um mapeamento da situação política dos municípios. Esse mapeamento é considerado útil por causa da complexidade envolvida nos estudos de políticas públicas nos municípios; há um extenso terreno a ser conhecido e os levantamentos primários podem ter uma função exploratória.

A reflexão a seguir apresentada é incipiente. Mas, mesmo assim, o presente ensaio foi elaborado no intuito de colaborar para o entendimento da descontinuidade político-administrativa nos municípios e seus possíveis efeitos sobre as políticas de saúde, em particular sobre a execução de programas de educação não formal.

\section{Definindo a descontinuidade político-administrativa}

O fenômeno da descontinuidade político-administrativa pode ser definido, conforme Nogueira ${ }^{11}$, basicamente pela

[...] interrupção de iniciativas, projetos, programas e obras, mudanças radicais de prioridades e engavetamento de planos futuros, sempre em função de um viés político, desprezando-se considerações sobre possíveis qualidades ou méritos que tenham as ações descontinuadas. Como conseqüência, tem-se o desperdício de recursos públicos, a perda de memória e saber institucional, o desânimo das equipes envolvidas e um aumento da tensão e da animosidade entre técnicos estáveis e gestores que vêm e vão ao sabor das eleições. (p. 13)

A descontinuidade, em instituições públicas, se refere basicamente ao aparato governamental de gestão, sendo uma consequência do preenchimento de cargos de confiança a cada mudança de governo ou troca de dirigentes ${ }^{12}$. Integram a descontinuidade fenômenos, tais como: a interrupção de projetos, de programas e obras, bem como de reavaliação de prioridades, em nível municipal. Neste sentido a descontinuidade é denominada de 'político-administrativa', onde o termo político é utilizado para designar os 'negócios públicos', mas não o fenômeno da alternância de pessoas ou partidos no comando do governo local. A alternância político-partidária é um fenômeno específico da competição em uma democracia representativa.

Especificando um pouco mais, no que tange à área da saúde, foi observada, pelos autores, uma série de fenômenos (interrupções ou atrasos) como, por exemplo:

1. Em programas de capacitação de agentes comunitários de saúde (ACS) e, também, de membros de conselhos municipais de saúde;

2. Na coleta de dados clínicos e pesquisa de campo; 
3. Em projetos de avaliação de metodologias ativas de ensino e aprendizagem;

4. Na coleta de dados por meio da aplicação de questionários;

5. Em programas e atividades de educação em saúde, como, por exemplo, de prevenção do diabetes e da hipertensão.

6. Em campanhas educativas e jornadas de conscientização dos usuários de serviço de saúde.

Os atrasos e interrupções acarretam prejuízos financeiros, organizacionais e pessoais. No caso das pesquisas ou projetos de extensão universitária, o desrespeito aos prazos para prestação de contas junto aos órgãos financiadores traz consequências desagradáveis. Usuários dos serviços de saúde, notadamente o público-alvo de campanhas educativas e de prevenção, bem como agentes de ACS, também são prejudicados. Em particular, no caso dos ACS, a descontinuidade afeta a capacidade de atendimento, gerando descontentamentos e estigmatização desses agentes, que são avaliados negativamente pela população.

Ora, uma vez definido o fenômeno da descontinuidade, cabe, agora, procurar refletir sobre suas possíveis causas. A principal alegação que, provavelmente, se possa fazer sobre a descontinuidade político-administrativa é que se trata de um fenômeno derivado da forma como se exercem as funções de governo no sistema político brasileiro.

\section{O sistema político brasileiro e os problemas de governabilidade e governança}

É importante salientar, a respeito do sistema político brasileiro, a dificuldade de se fazerem respeitar os valores políticos republicanos. Para maior clareza sobre o que é uma república, pode-se afirmar, segundo Bignotto ${ }^{13}$, que:

Embora tenhamos uma rica história constitucional, a separação entre o público e o privado nem sempre é percebida como um fato derivado das leis fundamentais e nela refletidos. De um lado, grupos ou partidos políticos que chegam ao poder costumam desconhecer o fato de que o aparato constitucional constitui um limite instransponível para suas ações. Agindo como grupo privado, vários atores políticos se comportam como se a vitória nas eleições significasse a posse da totalidade dos poderes do Estado. A confusão entre a esfera do governo e os domínios do Estado conduzem à crença de que a soberania popular, origem das leis em uma democracia, é apenas uma referência ideal, sem correspondência na realidade. Por outro lado, o próprio Estado parece reproduzir seus quadros [...] criando um grupo dirigente, que não reconhece limites para suas práticas, além daqueles inerentes às disputas políticas. (p. 84-5)

Uma república é um Estado organizado enquanto uma comunidade política. Comunidade, no caso, indica que os cidadãos, todos eles, governo ou governados, compartilham um conjunto de valores, de crenças, normalmente expressos em uma carta constitucional. De acordo com Huntington ${ }^{14}$, em um Estado republicano ou sistema cívico, existe um consenso moral a respeito de normas, regras, valores, e o reconhecimento de que existem interesses que são comuns a todos os cidadãos. Em um Estado republicano, existem laços de solidariedade e de lealdade, fundamentados em fatores diversos do estrito interesse individual, como, por exemplo: elementos afetivos, morais e ideológicos, crenças em valores e ideias, que orientam as suas condutas.

O sistema político brasileiro se caracteriza por ser, não um sistema cívico, mas um sistema pretoriano. Segundo Huntington ${ }^{14}$, em um sistema pretoriano, indivíduos e grupos de mais variados tipos fundamentam suas ações, predominantemente, a partir de seus próprios interesses específicos. Os princípios do consenso moral e dos interesses comuns não têm efetividade. Em um sistema pretoriano, a apropriação do aparato estatal para fins privados é uma prática recorrente. Indivíduos ou grupos entendem a esfera pública, o Estado e suas instituições, como um lugar a ser ocupado e explorado como uma propriedade privada.

O sistema político brasileiro indica, em suas características de sistema pretoriano, uma persistente tendência designada por Bignotto ${ }^{13}$, como a procedência do Estado sobre a sociedade civil. Esta tendência, pode se dizer, é uma herança histórica reforçada pelas experiências do Estado Novo (1937- 
1945) e o Regime Militar (1964-1985). Tal procedência indica que, na gênese e na implementação de políticas públicas, ainda não se verifica significativa participação social.

A procedência do Estado sobre a sociedade civil indica problemas referentes: 1) Ao desenvolvimento e aprimoramento dos mecanismos de participação social, que representa o aperfeiçoamento da governabilidade; 2) Ao funcionamento do aparato estatal, ou seja, à governança.

A governabilidade pode, segundo $\operatorname{Araújo}^{15}$ (p. 6), “[...] ser concebida como a autoridade política do Estado em si, entendida como a capacidade que este tem para agregar os múltiplos interesses dispersos pela sociedade e apresentar-Ihes um objetivo comum para os curto, médio e longo prazos".

Por governança, se deve entender o conjunto das capacidades que um governo possui para tomar decisões a respeito das políticas públicas, sobretudo no que diz respeito à implementação. A governança diz respeito ao aparato ou burocracia estatal e à sua capacidade gerencial ${ }^{16}$. Não se trata de negar a participação da sociedade civil nos processos de gênese e implementação das políticas públicas, mas, tão somente, de supor as funções específicas dos agentes e órgãos públicos. Boa governança significa, assim, eficiência governamental.

Qualquer esforço de aperfeiçoamento e desenvolvimento institucional para se efetivar o princípio republicano, deverá abranger: 1) O aparato estatal, a respeito do qual se deseja eficiência (boa governança); 2) As condições e garantias de mais participação política e social para garantir governabilidade. Assim, governo e sociedade devem fazer parte de um ideário de aperfeiçoamento em direção a uma democracia republicana.

\section{A área da Saúde e a municipalização}

A despeito do sistema político pretoriano, desde a Assembléia Nacional Constituinte (19871988), inicia-se uma nova fase das relações entre Estado e sociedade civil. Avritzer ${ }^{17}$ denomina, este novo momento, de fase da criação da interdependência política, a qual pode ser entendida como uma relação política em que, por meio de mecanismos, como a descentralização e a participação, os processos de tomada de decisão passam a contar com a necessidade de negociação e diálogo entre as partes interessadas. Ainda segundo Avritzer ${ }^{17}$, como exemplo desta fase de interdependência política, destaca-se o Artigo 198 da Constituição Federal que "[...] descreveu a saúde como um sistema integrado organizado de acordo com os seguintes princípios: (1) descentralização; (2) cuidado unificado com foco na prevenção; e (3) participação da sociedade civil nas deliberações de políticas" (p. 390).

A descentralização pode ser considerada como uma resposta para o desafio de se construir uma ordem democrática após anos de autoritarismo do Regime Militar. A nova ordem, com a Constituição de 1988, foi fundamentada em valores verificados comumente em países com experiências mais duradouras e consolidadas com a democracia. Foram garantidos os direitos civis, políticos e sociais que são o padrão daquilo que, no cenário internacional, é considerado como democracia ${ }^{18}$. A saúde e educação são exemplos importantes de direitos sociais.

A nova ordem democrática também reconheceu a necessidade de participação social nos processos de decisão, associando, aos mecanismos de representação política, certos procedimentos, tais como: a audiência pública, o orçamento participativo, as proposições legislativas por iniciativa popular. E a importância da participação foi reconhecida para todos os níveis da organização do Estado, ou seja, para a União, os Estados e Distrito Federal e os municípios, configurando, portanto, o princípio da descentralização.

$\mathrm{Na}$ área da saúde, o processo de criação dos conselhos municipais no âmbito do SUS foi uma iniciativa que representou uma adequação aos valores e critérios de governabilidade. Sob o signo da descentralização, da participação, a gestão da saúde foi planejada para contribuir com a garantia de direitos sociais e para o exercício consciente da própria cidadania democrática.

$\mathrm{Na}$ área da saúde, a procedência do Estado sobre a sociedade civil foi reconhecida como um obstáculo na medida em que seria necessário formar capital social que viabilizasse, da melhor forma possível, a participação. Foi reconhecida a necessidade de se promover o empoderamento dos atores envolvidos com a gestão por meio do desenvolvimento de capacidades, de competências, para o 
exercício da participação ${ }^{19}$. Como instrumento de empoderamento, não só de conselheiros, mas, também, de agentes de saúde e de usuários dos serviços públicos de saúde, vários estudos destacam a importância da educação não formal com o uso de metodologias ativas que visam permitir o desenvolvimento da reflexão e conscientização. Trata-se de um esforço de transformar todos os envolvidos com a saúde pública em cidadãos capazes de agir, executar tarefas institucionalmente definidas e usufruir de direitos de forma.

Assim, da criação do SUS até as definições concernentes ao 'empoderamento' e ao uso de metodologias ativas, a área da saúde esteve lidando com a questão da governabilidade, contribuindo de várias formas para o aperfeiçoamento da democracia. Na Figura 1, estão sintetizados os argumentos sobre a importância da área da saúde para a governabilidade democrática a partir da Constituição de 1988.

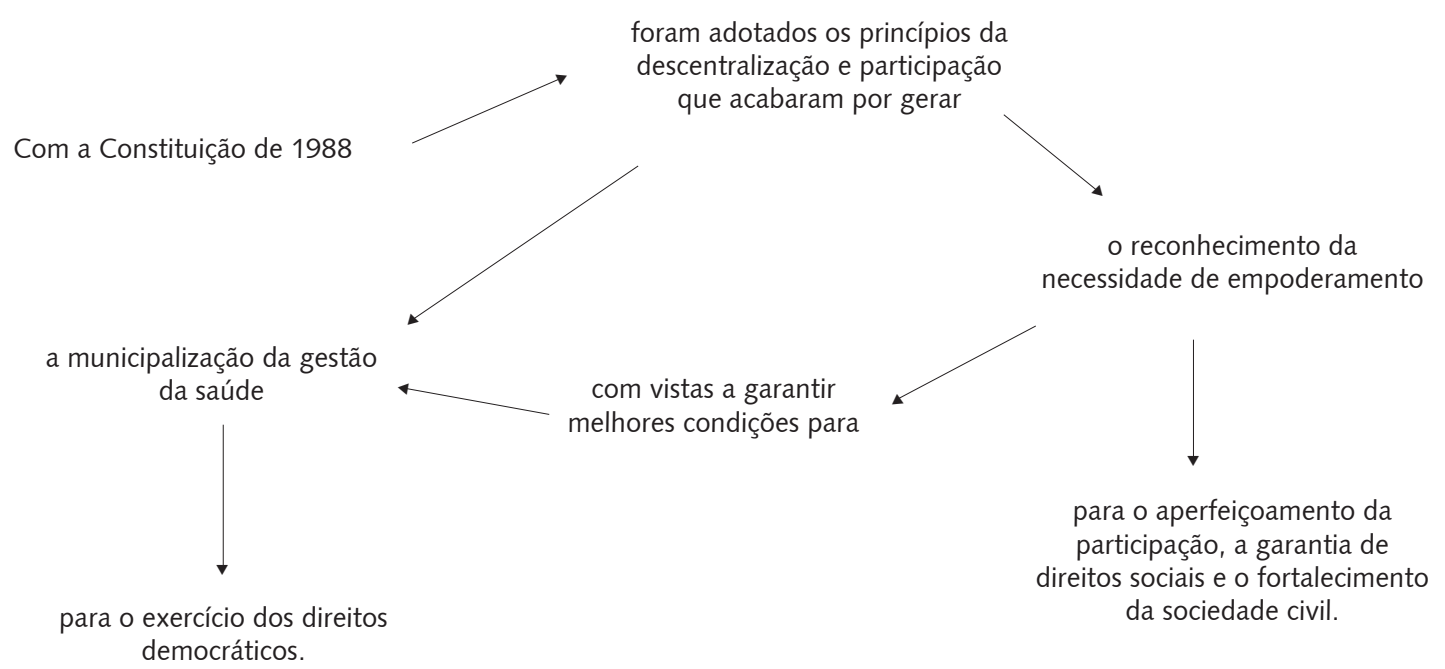

Figura 1. A área da saúde a partir da Constituição de 1988

A descentralização da gestão da saúde foi construída sobre o pressuposto de que, a partir de sua efetividade, seria possível a participação da sociedade civil, gerando uma melhoria do quadro geral de nossas instituições públicas. Mas, há aqui uma via de mão dupla, pois, se a descentralização é um meio para o fortalecimento da sociedade civil, não é menos razoável supor que uma sociedade civil forte é um pré-requisito para a ocorrência da descentralização que representaria o aperfeiçoamento da democracia. Tais relações são reconhecidas na literatura de políticas públicas produzida a partir dos anos $1990^{20}$.

O processo de municipalização da saúde, de implementação do SUS, acarreta um problema. De acordo com Fleury ${ }^{21}$ :

A operacionalização do SUS coloca em evidência alguns problemas, por exemplo, a questão do clientelismo e a grande permissividade de interesses políticos locais nas administrações municipais. O que se percebe é que no serviço público a continuidade ou não dos projetos é dada pelo interesse dos dirigentes e pelos interesses político-partidários. Também os cargos, como o de secretário municipal de saúde ou membros do Conselho Municipal de Saúde, muitas vezes são ocupados através de indicação do prefeito. (p. 77) 
As suposições aqui consideradas são as seguintes: 1) A descontinuidade político-administrativa é oriunda de falhas provenientes de limitações gerenciais do governo local, configurando, portanto, um problema de governança; 2) As falhas gerenciais incidem negativamente sobre a gestão da política de saúde, limitando a implementação da mesma; 3) As falhas gerenciais afetam, em particular, as ações que visam o "empoderamento", na medida em que dificultam os programas de educação não formal em saúde que se utilizam das metodologias ativas de ensino e aprendizagem, 4) Assim, o que é um problema gerencial, de governança, torna-se um problema de governabilidade quando afeta as ações voltadas para o empoderamento. Na Figura 2, encontra-se uma síntese destas suposições.

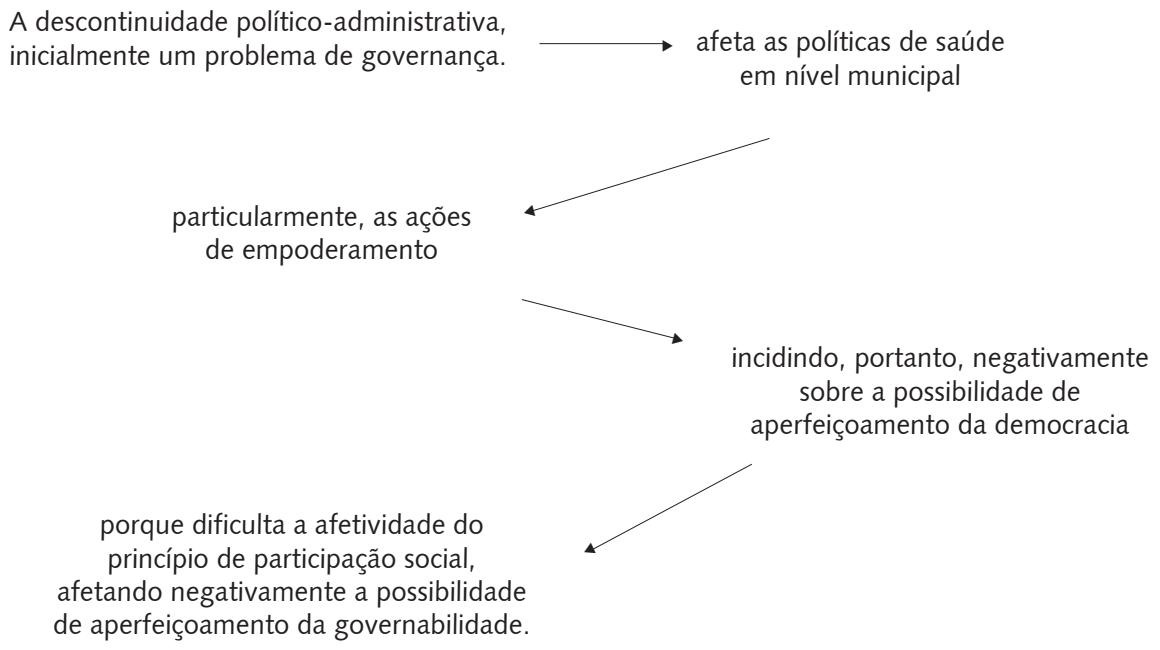

Figura 2. A descontinuidade e seus efeitos nas políticas municipais de saúde

A municipalização (descentralização) indica que a implementação de políticas públicas de saúde pode se relacionar aos problemas referentes à governabilidade e à governança, características de um sistema político pretoriano. Segundo Cotta et al. ${ }^{4}$, a implementação do SUS está à mercê de obstáculos provenientes da permeabilidade do setor da saúde frente ao clientelismo. No processo de municipalização, as políticas de saúde podem ser afetadas pela descontinuidade político-administrativa, um fenômeno decorrente dos problemas de governabilidade e de governança.

A seguir, serão apresentadas algumas considerações que conduzirão à proposição de um instrumento analítico, um modelo, que possa contribuir para reflexão e os estudos a respeito da municipalização e da descontinuidade político-administrativa que afeta as políticas de saúde.

\section{A gestão municipal da Saúde enquanto um problema e a proposição de um modelo analítico para levantamentos primários}

Em busca de alguma clareza teórico-conceitual, deve-se considerar, inicialmente, conforme alega Frey ${ }^{22}$, que " $[\ldots]$ estudos de políticas públicas no nível da política municipal exigem a realização de levantamentos primários sobre as dimensões 'politics' e 'polity' nos municípios escolhidos, indo desta maneira além da dimensão material das políticas setoriais" (p. 27).

Os levantamentos primários sugeridos por Frey ${ }^{22}$ são uma forma de gerar informações prévias que, no decorrer do tempo, possam constituir um mapa para a orientação dos pesquisadores, os 
quais estão à mercê de alterações das normas e regras que definem políticas públicas (dimensão da polity), mas, sobretudo, de alterações na composição das redes de atores e de instituições envolvidas com as políticas públicas, e, também, a rede de atores envolvidos com o processo político (dimensão da politics). Ou seja, Frey considera necessário que se procure obter e registrar informações sobre o contexto político de municípios, identificando as capacidades institucionais, os atores envolvidos nas disputas políticas, seus projetos, programas e possíveis padrões de ação. Os levantamentos primários, provavelmente, terão de ser feitos no decorrer da realização de pesquisas de campo. Assim, não se pode deixar de reconhecer a ocorrência de dificuldades, sobretudo porque os levantamentos implicam desvio de recursos materiais e uso do tempo reservado às pesquisas ${ }^{22}$.

A municipalização da gestão da saúde surtiu um efeito cujo reconhecimento é muito importante para o estudo e para a implementação das políticas de saúde, em particular para a utilização de metodologias ativas de ensino e aprendizagem em contextos de educação não formal, metodologias cuja aplicação também é objeto de avaliação científica. Não pode ser ignorada, pelas instituições universitárias, pelos agentes públicos e pelos formuladores e executores das políticas de saúde, a significativa complexidade do universo das políticas públicas de saúde, onde os municípios se tornam peças importantes para a geração de conhecimento. Donde, o reconhecimento, anteriormente apresentado, quanto à necessidade de levantamentos primários, apresenta-se como um elemento importante para a previsão dos efeitos da descontinuidade político-administrativa.

No intuito de contribuir para a reflexão sobre o fenômeno da descontinuidade em um universo de pesquisa complexo, é possível fazer uso de um modelo. Para Scharpf ${ }^{23}$, modelo é uma estrutura conceitual que nos oferece um guia para a realização de explorações empíricas ou de levantamentos primários. Um modelo apenas nos indica o que devemos investigar. É um primeiro passo em direção à aquisição de conhecimento sobre a constelação de atores (individuais e coletivos) que compõem a vida social e política em nível local.

Que modelo poderia ser utilizado para a realização de levantamentos primários? Sugere-se, aqui, que sejam considerados, como modelo (ou roteiro de investigação), os fatores que compõem o resultado da pesquisa realizada por Spink, Clemente e Keppke ${ }^{24}$. No Quadro 1, serão apresentados, por meio de sistematização e adaptação de termos, os elementos que, uma vez ausentes ou insuficientes, podem contribuir para a ocorrência da descontinuidade político-administrativa.

Os fatores eleitoral, interinstitucional e político-institucional indicam a existência de compromissos entre os poderes municipais instituídos (prefeitura e câmara dos vereadores) e o eleitorado, sejam indivíduos ou grupos. Compromissos apontam para a ocorrência da participação e a prática descentralizada do poder. Apontam para a ocorrência do diálogo e negociações para a solução de problemas e escolha de soluções. Assim, o fator governabilidade (a capacidade de decisão e ação política pelo exercício democrático) é analiticamente contemplado. A ausência de, pelo menos, um destes fatores talvez seja suficiente para indicar a ocorrência de descontinuidade político-administrativa,

Quadro 1. Fatores referentes ao governo municipal a serem considerados na realização de levantamentos primários

\begin{tabular}{|l|l|}
\hline \multicolumn{1}{|c|}{ Fator } & \multicolumn{1}{c|}{ Caracterização } \\
\hline Eleitoral & $\begin{array}{l}\text { Cumprimento de compromissos de campanha ou de plataformas de governo previamente definidos, o } \\
\text { que indica a existência de grupos políticos bem articulados e comprometidos com a gestão pública. }\end{array}$ \\
\hline Interinstitucional & $\begin{array}{l}\text { Parcerias com instituições e organizações públicas ou privadas, o que aumenta as chances de que os } \\
\text { programas implementados possam ter impacto positivo junto aos cidadãos }\end{array}$ \\
\hline Político-Institucional & A existência de grupos que pressionam o governo local, o qual, por sua vez, responde às pressões \\
\hline Técnico & $\begin{array}{l}\text { Existência de uma administração pública eficiente, organizada de acordo com princípios gerenciais } \\
\text { racionalmente planejados, capaz de alcançar eficiência na implementação de políticas públicas }\end{array}$ \\
\hline
\end{tabular}

Fonte: Spink, Clemente e Keppke ${ }^{24}$. 
exatamente na medida em que a falta de compromissos entre os poderes instituídos e o eleitorado dá margem para interrupções, mau funcionamento ou paralisações de programas, projetos ou serviços.

O fator técnico diz respeito à governança, ou seja, diz respeito às capacidades administrativas do poder público municipal, abarcando as secretarias municipais, os demais órgãos do Executivo, bem como o quadro de funcionários do Legislativo. O planejamento das contas públicas, a previsão de gastos, a capacidade de elaboração de projetos para aquisição de recursos junto às instâncias federal e estadual, a capacidade de elaboração de projetos de lei adequados à legislação vigente, são exemplos de ações que carecem de capacidade técnica e gerencial.

A instância da administração pública (o fator técnico), se for analisada em si mesma, sem relação com os demais fatores, não é capaz de fundamentar quaisquer considerações ou análises sobre a governabilidade. Por outro lado, a análise da governabilidade não pode prescindir de considerações sobre a administração pública municipal, sob risco de não possibilitar um levantamento adequado do quadro político-institucional.

Seguindo o roteiro de investigação apresentado no Quadro 1, considerando, especificamente, as políticas municipais de saúde, e, em particular, os programas de educação não formal, a realização de levantamentos primários poderá considerar alguns elementos, tais como:

- Quanto à governabilidade (fatores eleitoral, político-institucional e interinstitucional): a composição e a atuação do conselho municipal de saúde; a existência de projetos de políticas públicas de saúde e diagnósticos sobre suas respectivas implementações; a ocorrência de programas de conscientização e educação dos usuários dos serviços de saúde; a existência de parcerias do poder público com outras instituições, bem como a implementação de capacitação para os agentes comunitários de saúde e para os conselheiros; a ocorrência de eventos ou manifestações que indiquem insatisfação ou crítica ao poder público, tais como, uma comissão parlamentar de inquérito (CPI), ações judiciais e críticas veiculadas nos meios de comunicação.

- Quanto à governança (fator técnico): a composição do quadro de funcionários públicos, notadamente no que diz respeito à existência de planos de carreira; a formação e preparo técnico dos ocupantes dos cargos que envolvem gerência e planejamento; as finanças públicas e planejamento orçamentário; a ocorrência de CPI, de ações judiciais e críticas veiculadas nos meios de comunicação.

Assim, em síntese, pode-se afirmar que, com a ausência de grupos políticos eficientes e compromissados com o trato da gestão de assuntos públicos (fator eleitoral), bem como a ausência de eficiência gerencial (fator técnico), de redes institucionais (fator interinstitucional) e de grupos sociais organizados e capazes de participar de alguma forma (fator político-institucional), há a possibilidade de ocorrência da descontinuidade político-administrativa.

A partir da realização de levantamentos primários, é possível supor que, progressivamente, serão sistematizadas informações institucionais envolvendo microrregiões e, em escala crescente, regiões administrativas nos Estados, e assim por diante.

\section{Considerações finais}

Por certo, a descontinuidade político-administrativa nos municípios é um fenômeno complexo. Aqueles que lidam com pesquisas ou extensão universitária, com a prestação de serviços públicos e, em suma, todos os envolvidos de uma forma ou de outra com a área da saúde, são afetados pelo fenômeno de uma ou outra. Um modo de responder à presença evidente do fenômeno é transformando-o em objeto de reflexão.

Os levantamentos primários podem ser um passo inicial em direção à formulação de predições sobre a probabilidade de ocorrência da descontinuidade político-administrativa. Tais predições podem representar, analiticamente, um instrumento útil para o planejamento e execução de projetos de pesquisa e extensão. A possibilidade de que se possa ter algum controle ou previsão sobre a descontinuidade também pode ser importante para a implementação das políticas públicas de saúde. É possível, também, que a descontinuidade político-administrativa figure enquanto variável, para além dos levantamentos primários, em pesquisas na área da saúde. 
Em especial, a possibilidade de predição deve ser encarada como um instrumento útil a serviço dos programas de educação não formal em saúde por meio do uso de metodologias ativas de ensino e aprendizagem. A educação não formal é crucial para a prática do empoderamento. E sem o empoderamento, a participação social na gestão da saúde fica comprometida, visto que a mesma não é algo natural, mas o resultado de uma cultura a ser solidificada por intermédio da formação de capacidades.

A ênfase dada ao empoderamento e aos programas de educação não formal em saúde, na verdade, é algo decorrente de um reconhecimento: a importância do aperfeiçoamento da governabilidade, dos mecanismos de participação e de decisão. Os esforços iniciados com o Movimento de Reforma Sanitária, e que se encontram reconhecidos na Constituição de 1988, no sentido de universalização do direito à saúde, carecem de plena realização e efetivação nos municípios. A municipalização (descentralização), reconhecida como fator representativo do aperfeiçoamento da governabilidade, da democracia, precisa frutificar. Para tanto, entender os mecanismos causais da descontinuidade político-administrativa é uma forma de contribuir para o aperfeiçoamento da democracia.

\section{Agradecimento}

O presente trabalho foi motivado, sobretudo, pelas experiências com a descontinuidade político-administrativa no desenvolvimento do projeto "Adesão ao tratamento da hipertensão arterial: o papel estratégico da educação em saúde e nutrição na atenção primária", apoiado pela Fapemig (Edital 14/2012 - Programa Pesquisa Para o SUS PPSUS-REDE. Processo: CDS-APQ-03594-12) e pela Capes (AUX - PE - Pro-Ensino Saúde 2034/2010, Processo: 23038.009788.12010-78).

\section{Colaboradores}

Juliana Costa Machado responsabilizou-se por todas as etapas do trabalho. Rosângela Minardi Mitre Cotta responsabilizou-se pela revisão do material referente às políticas públicas de saúde e a revisão das análises desenvolvidas no artigo. Jeferson Boechat Soares auxiliou na revisão do material referente à política e administração pública. 


\section{Referências}

1. Arretche MTS. Estado federativo e políticas sociais: determinantes da descentralização. São Paulo: Revam; 2000.

2. Draibe SM. As políticas sociais nos anos 90. In: Baumann $R$, organizador. Brasil: uma década em transição. Rio de Janeiro: Editora Campus; 1999. p. 101-42.

3. Braga IF. A sociedade civil e as políticas de saúde no Brasil dos anos 80 à primeira década do século XXI. In: Morosini MVGC, Reis JRF, organizadores. Sociedade, estado e direito à saúde. Rio de Janeiro: EPSJV, Fiocruz; 2007. p. 81-101.

4. Cotta RMM, Mendes FF, Muniz JN. Descentralização das políticas públicas de saúde: do imaginário ao real. Viçosa: Editora UFV; 1998.

5. Cotta RMM, Martins PC, Batista RS, Franceschini SCC, Priori SE, Mendes FF. O controle social em cena: refletindo sobre a participação popular no contexto dos conselhos de saúde. Physis. 2011; 21(3):1121-38.

6. Correia MVC. Que controle social? Os conselhos de saúde como instrumentos. Rio de Janeiro: Fiocruz; 2003.

7. Carvalho GCM. Participação da comunidade na saúde. Passo Fundo: IFBE, CEAP; 2007.

8. Ministério da Saúde. Conselho Nacional da Saúde. Política nacional de educação permanente para o controle no Sistema Único de Saúde (SUS). Brasília (DF): CNS; 2007.

9. Putnam RD. Comunidade e democracia: a experiência da Itália moderna. 4a ed. Rio de Janeiro: FGV Editora; 2005.

10. Arretche MTS. Financiamento federal e gestão local de políticas sociais: o difícil equilíbrio entre regulação, responsabilidade e autonomia. Cienc Saude Colet. 2003; $8(2): 331-45$.

11. Nogueira FA. Continuidade e descontinuidade administrativa em governos locais: fatores que sustentam a ação pública ao longo dos anos [dissertação]. São Paulo (SP): Escola de Administração de Empresas de São Paulo; 2006.

12. Spink P. Continuidade e descontinuidade em organizações públicas: um paradoxo democrático. Cad Fundap. 1987; 7(13):57-65.

13. Bignotto N. Corrupção e estado de direito. In: Avritzer L, Anastasia F, organizadores. Reforma política no Brasil. Belo Horizonte: Editora UFMG; 2006. p. 82-5.

14. Huntington S. Political order in changing societies. New Haven: Yale University Press; 1969.

15. Araújo VC. A caracterização de governabilidade e governança, da sua relação entre si e com o conjunto da reforma do estado e de seu aparelho. Brasília (DF): Enap; 2002. (Texto para discussão, n 45).

16. Diniz E. Governabilidade, governance e reforma do Estado: considerações sobre o novo paradigma. Rev Serv Publico. 1996; 120(2):5-21.

17. Avritzer L. Sociedade civil e Estado no Brasil: da autonomia à interdependência política. Opin Publica. 2012; 18(2):383-98.

18. Marshall TH. Cidadania, classe social e status. Rio de Janeiro: Zahar; 1976.

19. Sen A. Development as freedom. Oxford: Oxford University Press; 1999.

20. Spink PK, Clemente R, Keppke R. Governo local: o mito da descentralização e as novas práticas de governança. Rev Adm. 1999; 34(1):61-9. 
21. Fleury S. A utopia revisitada. Rio de Janeiro: Abrasco; 1995.

22. Frey K. Análise de políticas públicas: algumas reflexões conceituais e suas implicações para a situação brasileira. Florianópolis: PPGSP, UFSC; 1999. (Cadernos de Pesquisa, nº 18).

23. Scharpf FW. Games real actors play. Oxford: Westview Press; 1997.

24. Spink PK, Clemente R, Keppke R. Continuidade e descontinuidade administrativa: uma análise de fatores que contribuem para a manutenção de programas, projetos e atividades públicas de êxito em governos locais brasileiros. São Paulo: Fundação Getúlio Vargas; 2001. 
A descontinuidade político-administrativa apresenta-se como um fenômeno do sistema político brasileiro, notadamente em âmbito municipal. Com os esforços de descentralização e municipalização definidos pela Constituição de 1988, o processo de implementação das políticas de saúde foi afetado pela descontinuidade, causando prejuízos, entre os quais, atrasos e interrupções nos programas de educação não formal que são importantes para a promoção do empoderamento. A título de proposição para a reflexão, é apresentado um modelo para a realização de levantamentos primários nos municípios. Neste modelo são considerados quatro fatores: eleitoral, técnico, interinstitucional, político-institucional. Esses fatores se referem à organização da política nos níveis da governabilidade e governança. O objetivo deste ensaio é contribuir para o entendimento do fenômeno da descontinuidade político-administrativa verificada nos municípios brasileiros após a implantação do Sistema Único de Saúde (SUS).

Palavras-chave: Municipalização. Descontinuidade político-administrativa. SUS.

\section{Reflections on the process of municipalization of healthcare policies: the issue of political and administrative discontinuity}

Political and administrative discontinuity is a phenomenon within the Brazilian political system, notably in the municipal sphere. Through the efforts towards decentralization and municipalization that were defined by the 1988 constitution, the process of health policy implementation has been affected by discontinuity. This has causing damage, including delays and interruptions in non-formal education programs that are important for promoting empowerment. As a proposal for reflection, a model for conducting primary surveys in municipalities is presented here. Four factors are considered in this model: electoral, technical, interinstitutional and political-institutional. These factors refer to policy organization at the levels of governability and governance. The objective of this essay was to contribute towards understanding the phenomenon of political and administrative discontinuity observed in Brazilian municipalities since the implementation of the Brazilian Health System (SUS).

Keywords: Municipalization. Political and administrative discontinuity. SUS.

\section{Reflexiones sobre el proceso de municipalización de las políticas de salud:} la cuestión de la discontinuidad político-administrativa

La discontinuidad político-administrativa se presenta como un fenómeno en el sistema político brasileño, principalmente en el ámbito municipal. Con los esfuerzos de descentralización y municipalización definidos por la Constitución de 1988, el proceso de implementación de las políticas de salud fue afectado por la discontinuidad, causando perjuicios, entre ellos atrasos e interrupciones en los programas de educación no formal que son importantes para la promoción del empoderamiento. A título de propuesta para la reflexión, se presenta un modelo para la realización de levantamientos primarios en los municipios. En este modelo se consideran cuatro factores: electoral, técnico, interinstitucional, político institucional. Esos factores se refieren a la organización de la política en los niveles de la gobernabilidad y de la gobernanza. El objetivo de este ensayo es contribuir para el entendimiento del fenómeno de la discontinuidad político-administrativa verificada en los municipios brasileños después de la implantación del Sistema Brasileño de Salud (SUS).

Palabras clave: Municipalización. Discontinuidad político-administrativa. SUS. 